\title{
ELSEVIER_CARBON_8465
}

\section{Preparation of homogeneous CNT coatings in insulating capillary tubes by an innovative electrochemically-assisted method}

\section{Carlos Sanchis $^{\mathrm{a}}$}

Ángel Berenguer-Murcia ${ }^{b}$

Ramiro Ruiz-Rosas

Emilia Morallón ${ }^{\mathrm{a}}$

Diego Cazorla-Amorós b, $^{\text {, }}$

cazorla@ua.es

aDepartamento de Química-Física e Instituto Universitario de Materiales, University of Alicante, P.O. Box 99, San Vicente del Raspeig E-03080, Spain

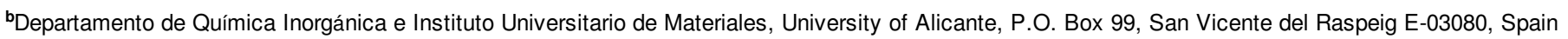

${ }^{*}$ Corresponding author.

\section{Abstract}

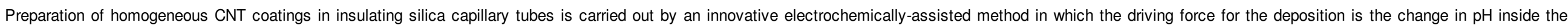
confined space between the inner electrode and the capillary walls. This method represents a great advancement in the development of CNT coatings following a simple, cost-effective methodology.

\section{Introduction}

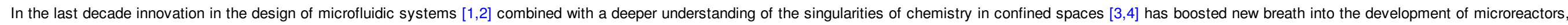

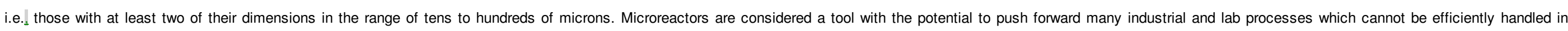

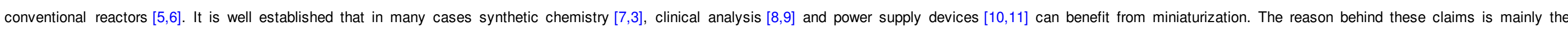

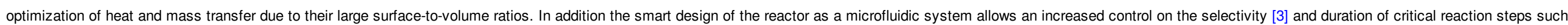

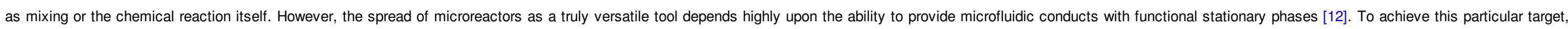
new strategies must still be developed in order to enable the generation of homogeneous coatings with the desired thickness throughout the microfluidic pipes without clogging the system.

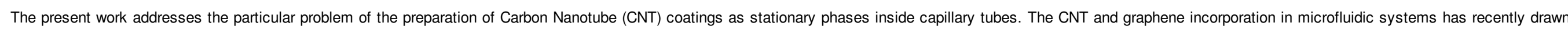

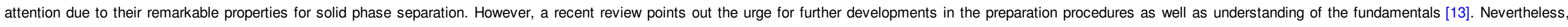

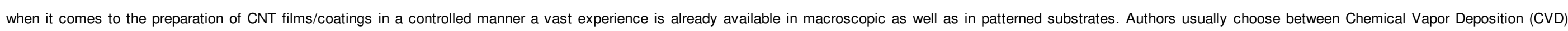

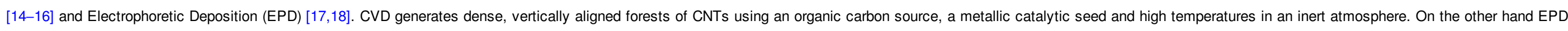

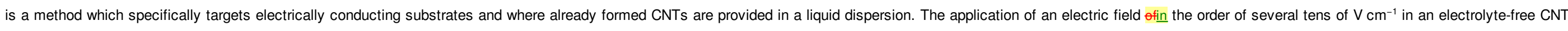

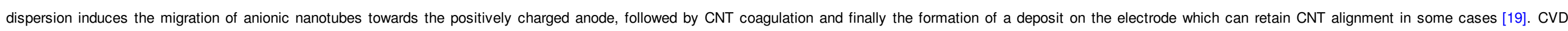

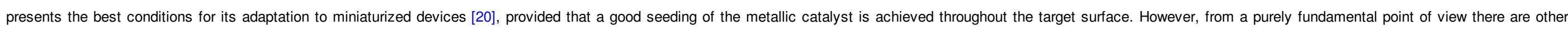

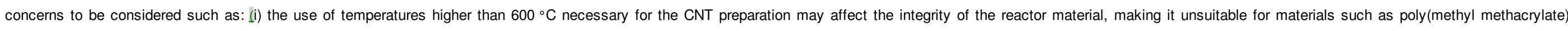

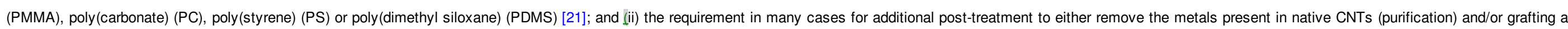
supported catalyst, which can be complicated due to low accessibility and the corrosive action of acidic solutions used in the purification step. 


\section{ELSEVIER_CARBON_8465}

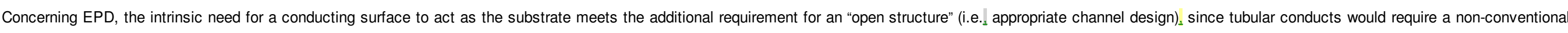
electrode configuration in order to obtain a homogeneous distribution of the electric field along the inner cavity. These two limitations make EPD suitable for few specialty microreactor designs.

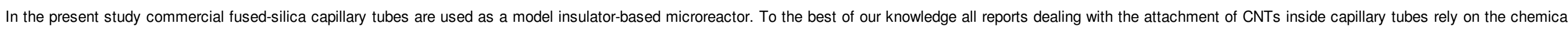

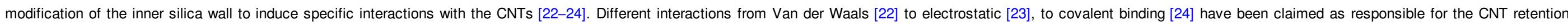

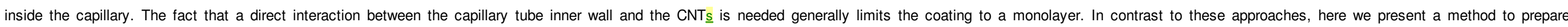

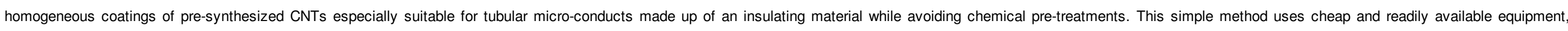

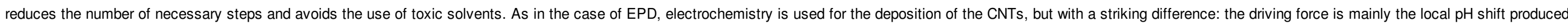

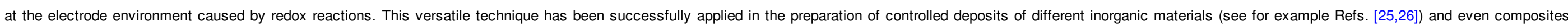

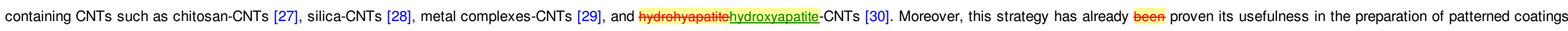

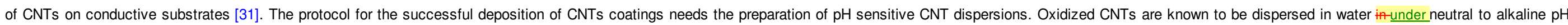

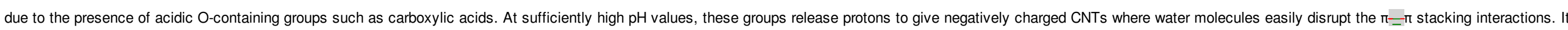

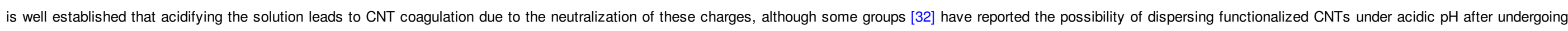

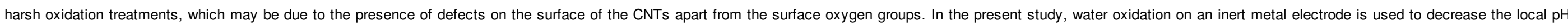
inside the insulating capillary tube.

\section{Experimental}

\subsection{Carbon nanotube functionalization}

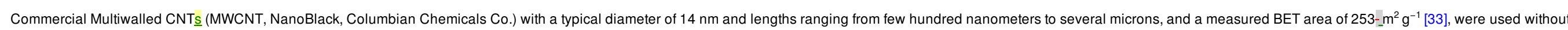

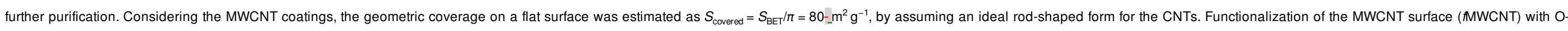

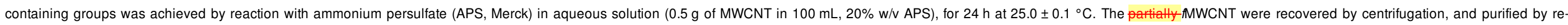

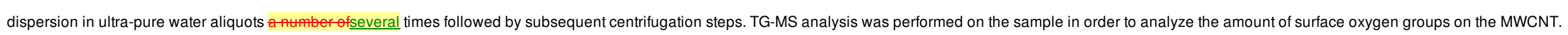

\subsection{Preparation and characterization of the Pd catalyst}

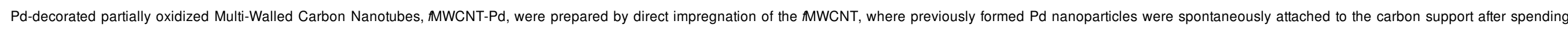

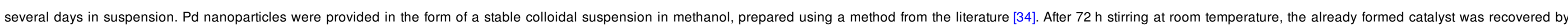
filtering. Non-specifically attached Pd and capping agent excess were removed by subsequent washing with refrigerated water-ethanol mixture prepared with equivalent volumes.

\subsection{Preparation of stable fMWCNT dispersions in water and estimation of their concentration}

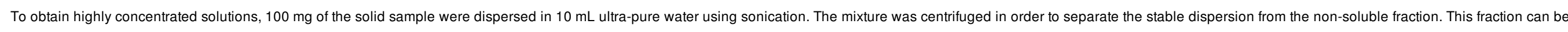

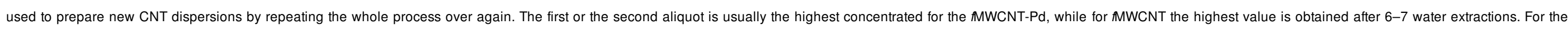

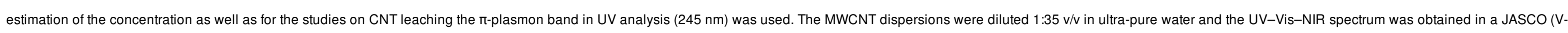

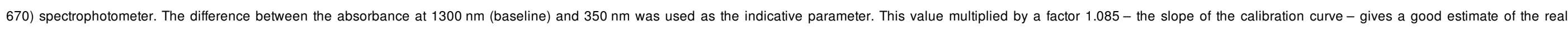
concentration in $\mathrm{mg} \mathrm{mL}^{-1}$.

\subsection{Electrochemically-assisted fMWCNT deposition}

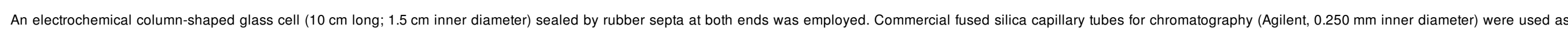

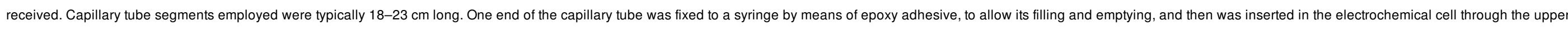

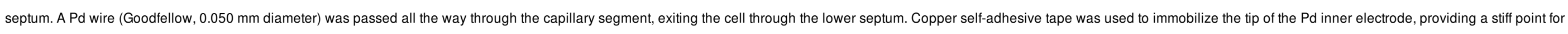




\section{ELSEVIER_CARBON_8465}

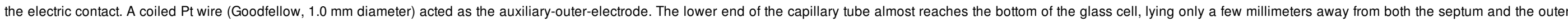

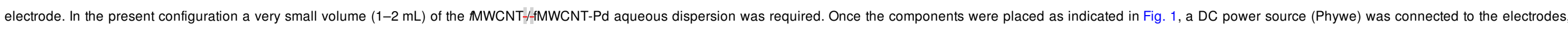

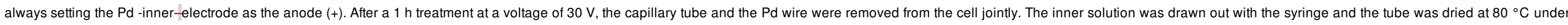
dynamic vacuum before carefully removing the wire to avoid scratching of the CNT coating

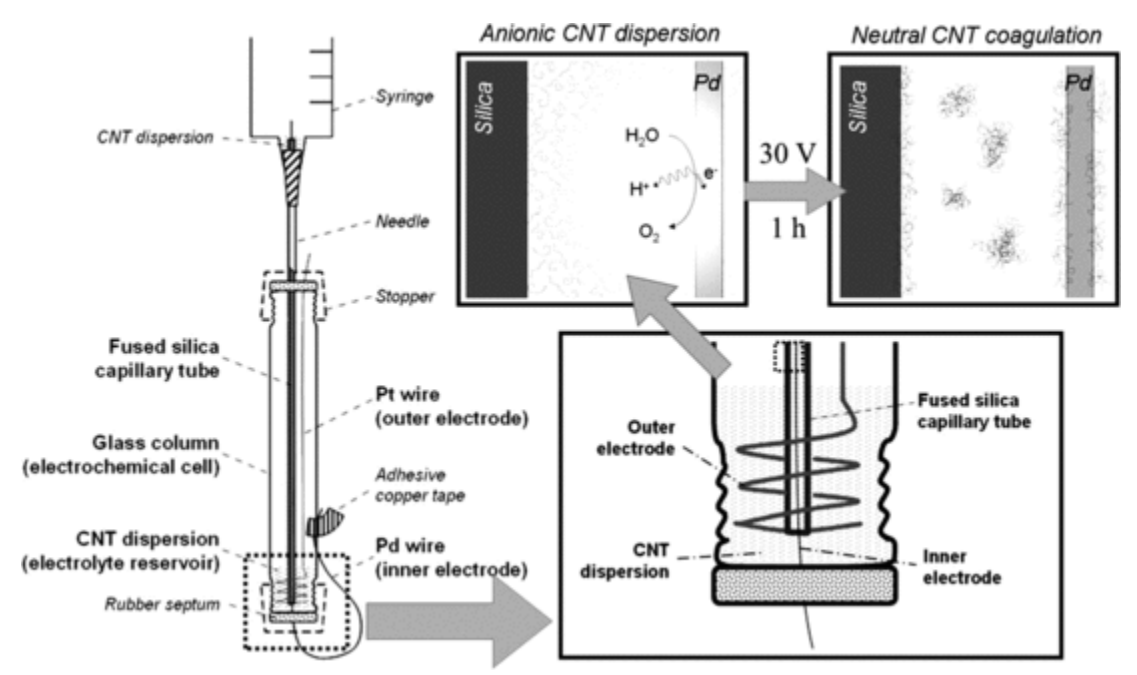

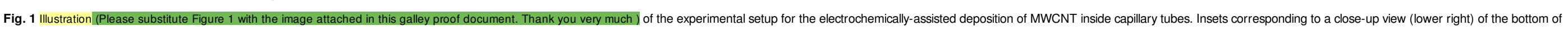
the cell and the suggested deposition process (top right).

\subsection{Sample characterization}

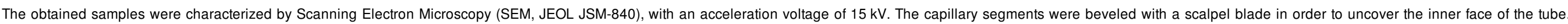
Samples were coated with a thin gold layer prior to analysis. The CNTs samples were also characterized by Transmission Electron Microscopy (TEM, JEOL JEM-2010) with an accelerating voltage of 200 kV.

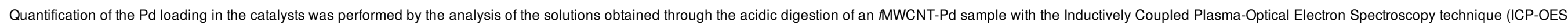
Perkin Elmer, Optima 4300 DV)

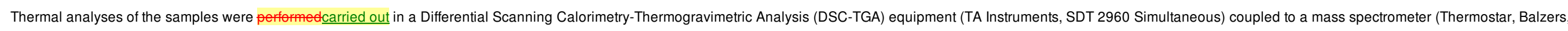
GSD 300 T3). About $10 \mathrm{mg}$ of the sample were heated up to $940^{\circ} \mathrm{C}$ (heating rate of $10^{\circ} \mathrm{C} / \mathrm{min}$ ) under a helium flow rate of $100 \mathrm{~mL} / \mathrm{min}$.

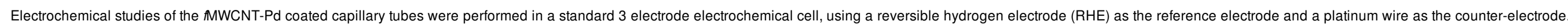

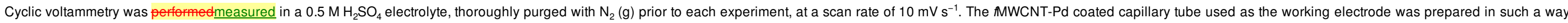

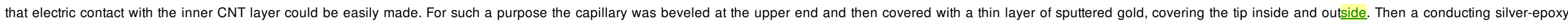

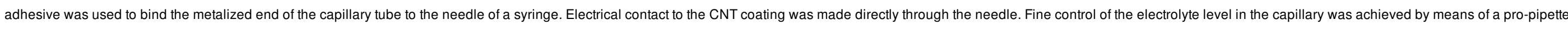
adapted to the syringe through a flexible rubber conduct. An eDAQ potentiostat and recorder were used to erform record the cyclic voltammetryogram.

\section{Results and discussion}

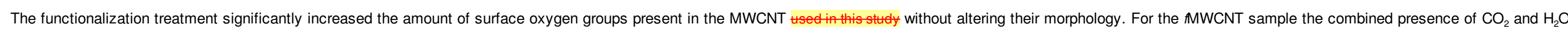

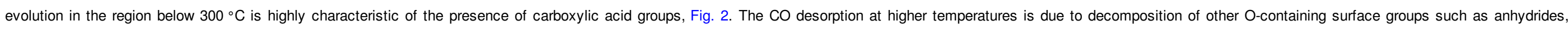




\section{ELSEVIER_CARBON_8465}

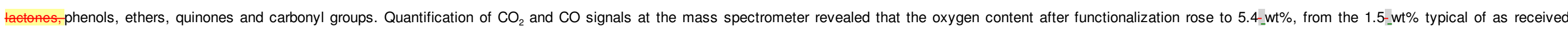
MWCNT.

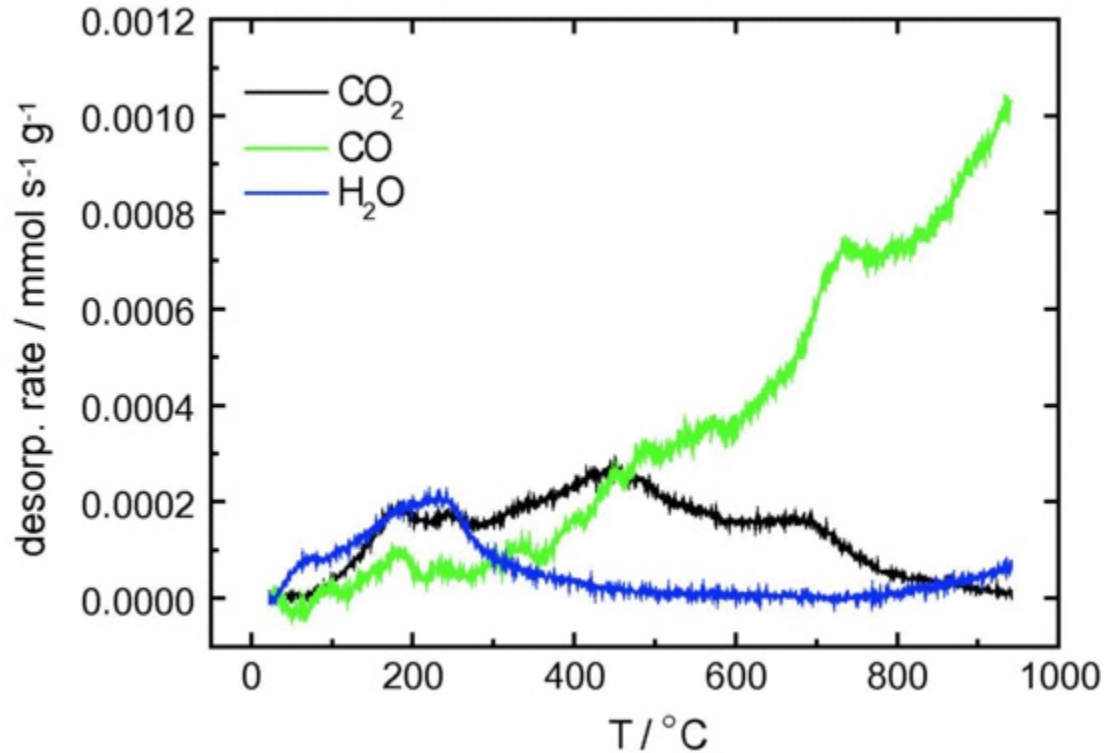

Fig. $2 \mathrm{CO}_{2}, \mathrm{CO}$ and $\mathrm{H}_{2} \mathrm{O}$ desorption rate profiles as a function of the temperature for the fMWCNT sample. (A color version of this figure can be viewed online.)

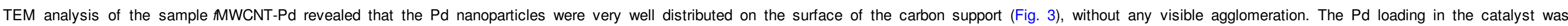
$1.33 \pm 0.02-w t \%$ according to the ICP-OES analysis. 


\section{ELSEVIER_CARBON_8465}

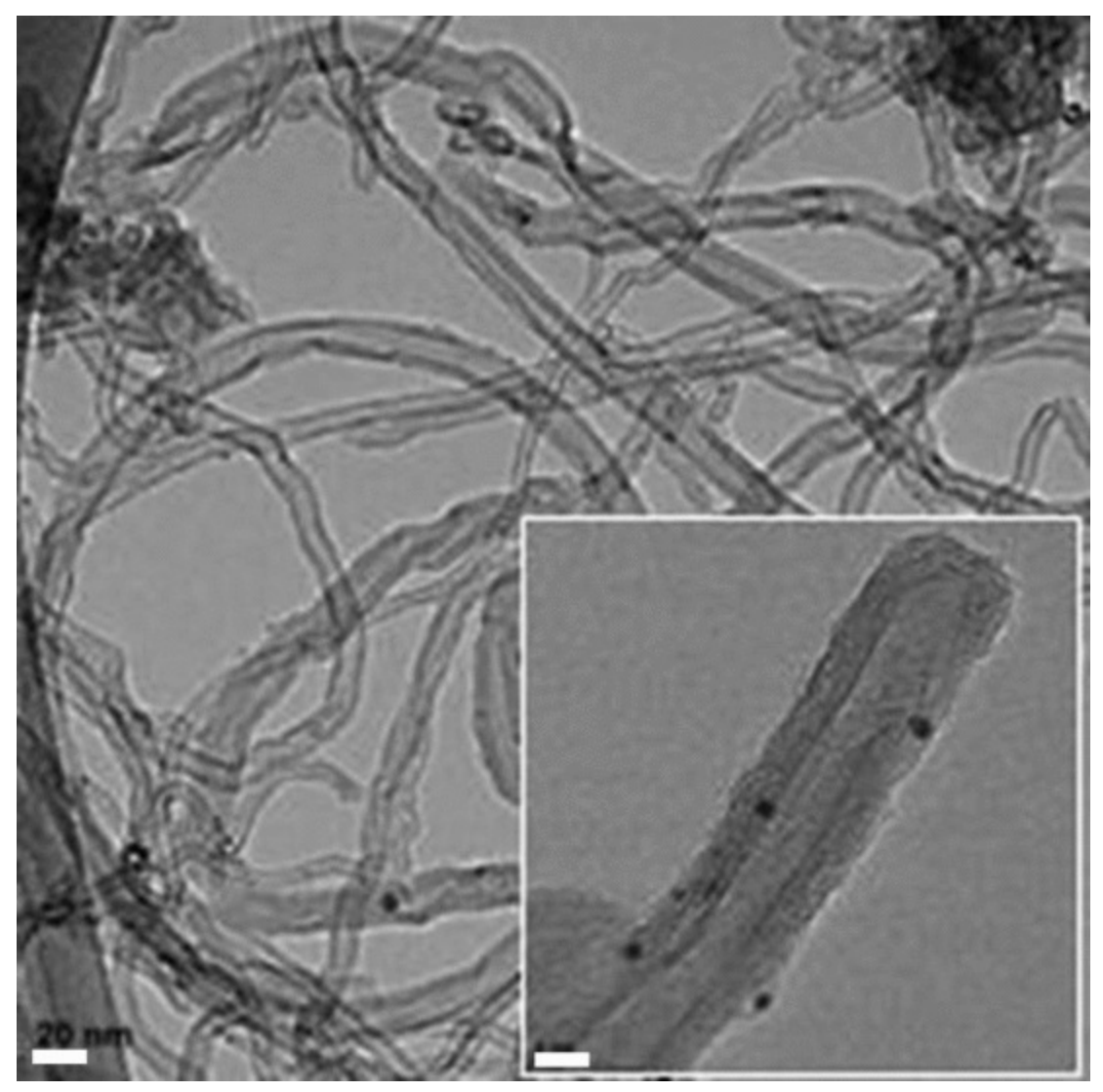

Fig. 3 TEM images of AMWCNT-Pd deposited from a stable water dispersion. Scale bar: $20 \mathrm{~nm}$; inset scale bar: $5 \mathrm{~nm}$.

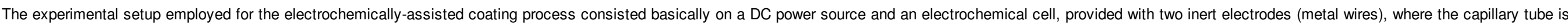

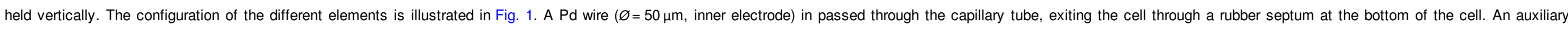

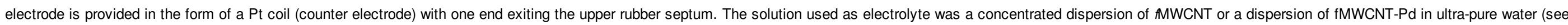
Section 2.3).

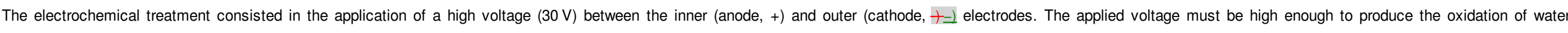

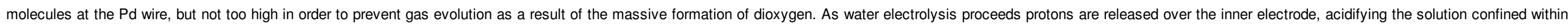
the capillary tube, Fig. 1.

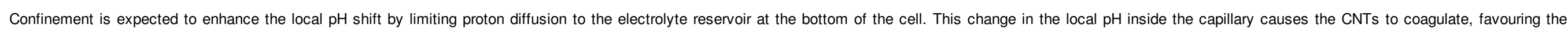

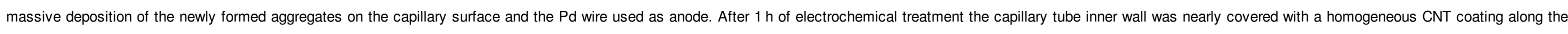

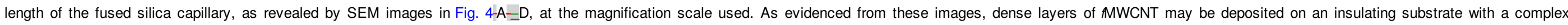

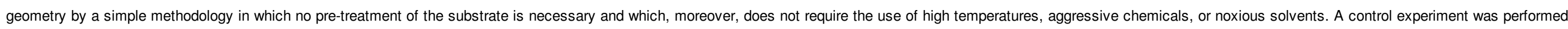

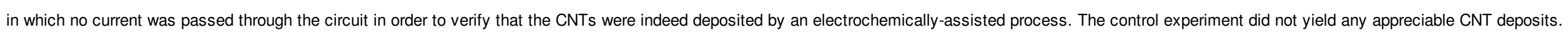




\section{ELSEVIER_CARBON_8465}

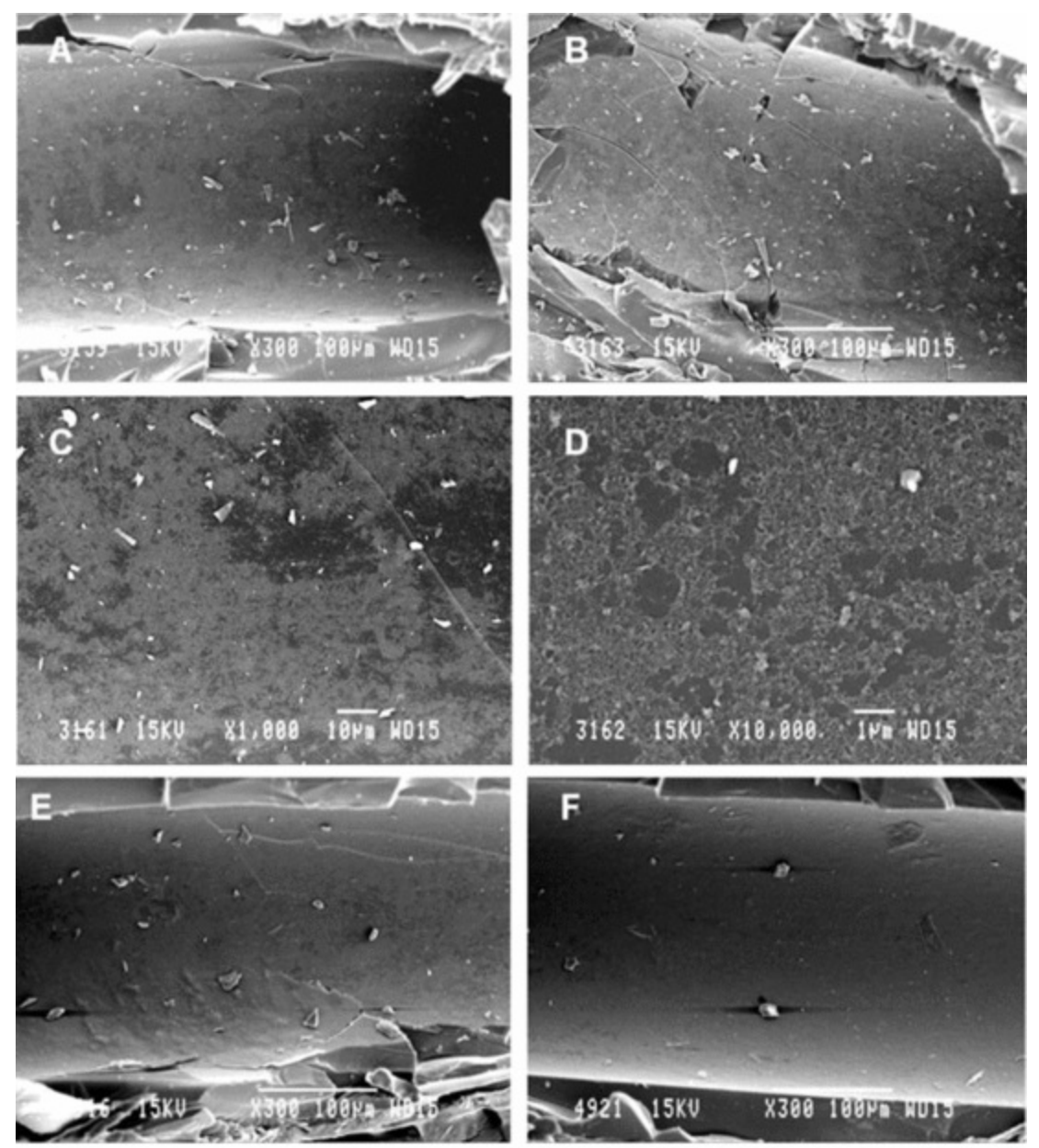

G

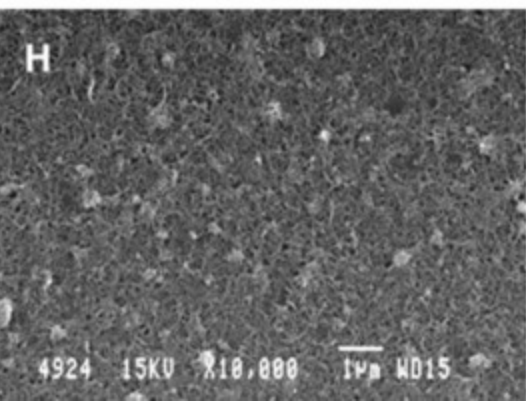

$4922 \quad 15 \mathrm{KU} \quad \mathrm{X1}, 88 \mathrm{~B} \quad \overline{18 \mathrm{NO}}, \mathrm{KD} 15$

Fig. 4 SEM images of the inner wall of AMWCNT (A-D) and AMWCNT-Pd (E-H) coated capillary tubes. Silica splinters (sharp-edged fragments) and fractures are artifacts produced as a result of the incision with the scalpel blade.

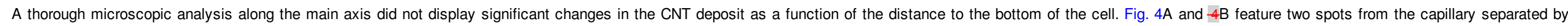
$10 \mathrm{~cm}$ with almost identical coverage. 


\section{ELSEVIER_CARBON_8465}

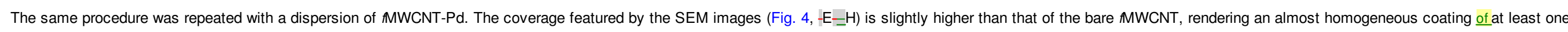

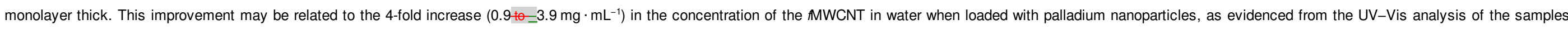

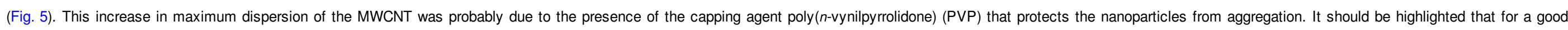
coverage of the capillary tube, working electrolyte solutions should be as concentrated as possible, thus the necessity of increasing the amount of surface oxygen-containing groups of the starting material.

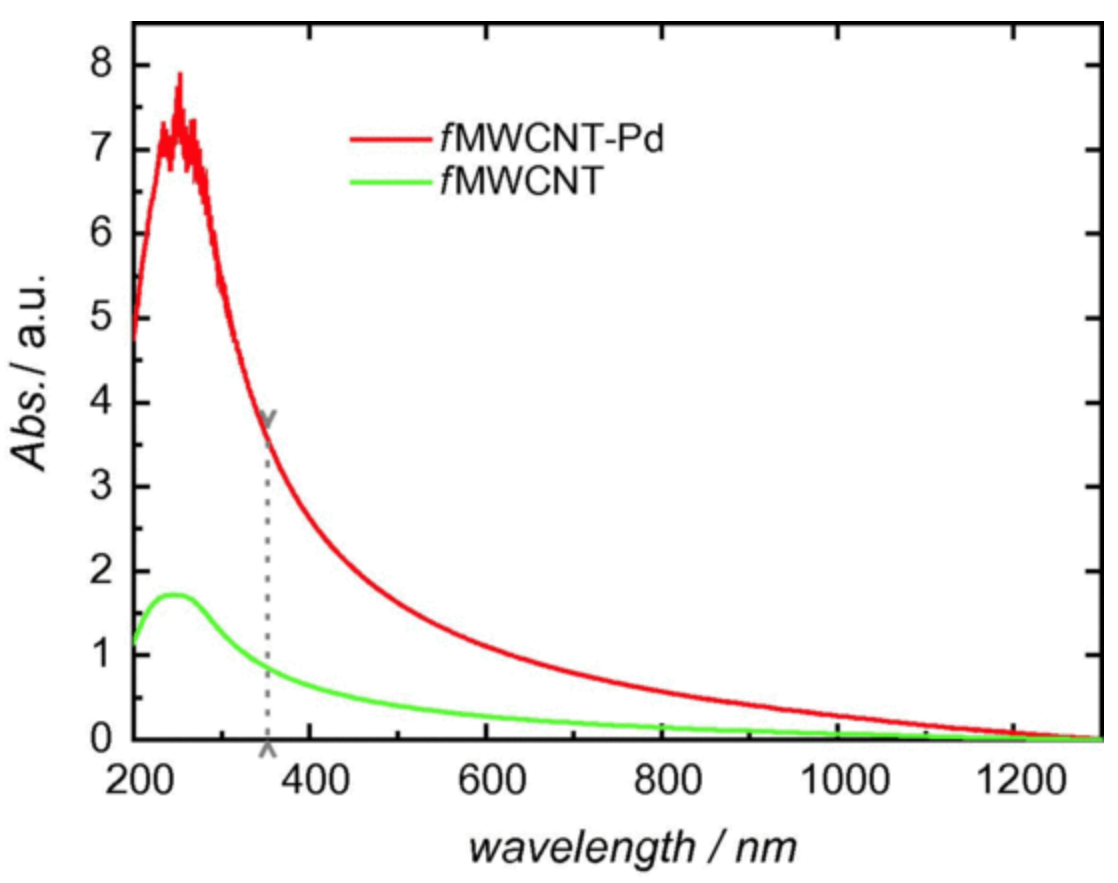

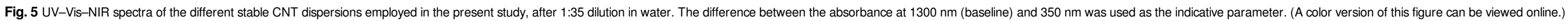

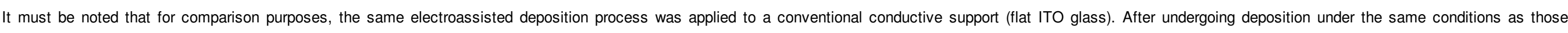

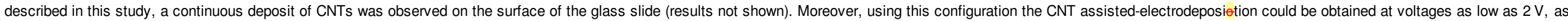
reported by Aziz and Yang [31]. In this respect, the use of comparatively high voltages is necessary when using the fused silica capillaries due to their being insulating materials.

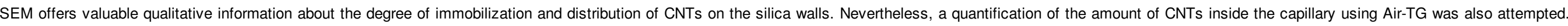

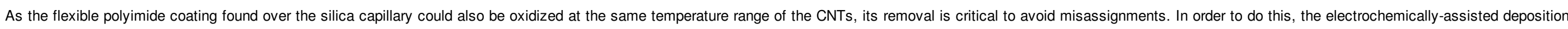

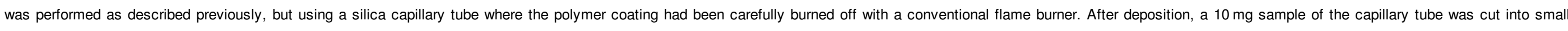

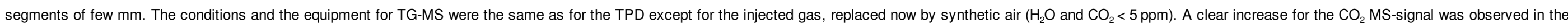

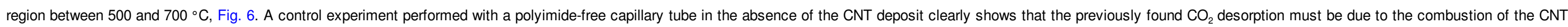
coating. The area under the peak was quantified giving a $0.023-w t \%$ for the CNT deposit related to the total mass of the coated capillary tube. 


\section{ELSEVIER_CARBON_8465}

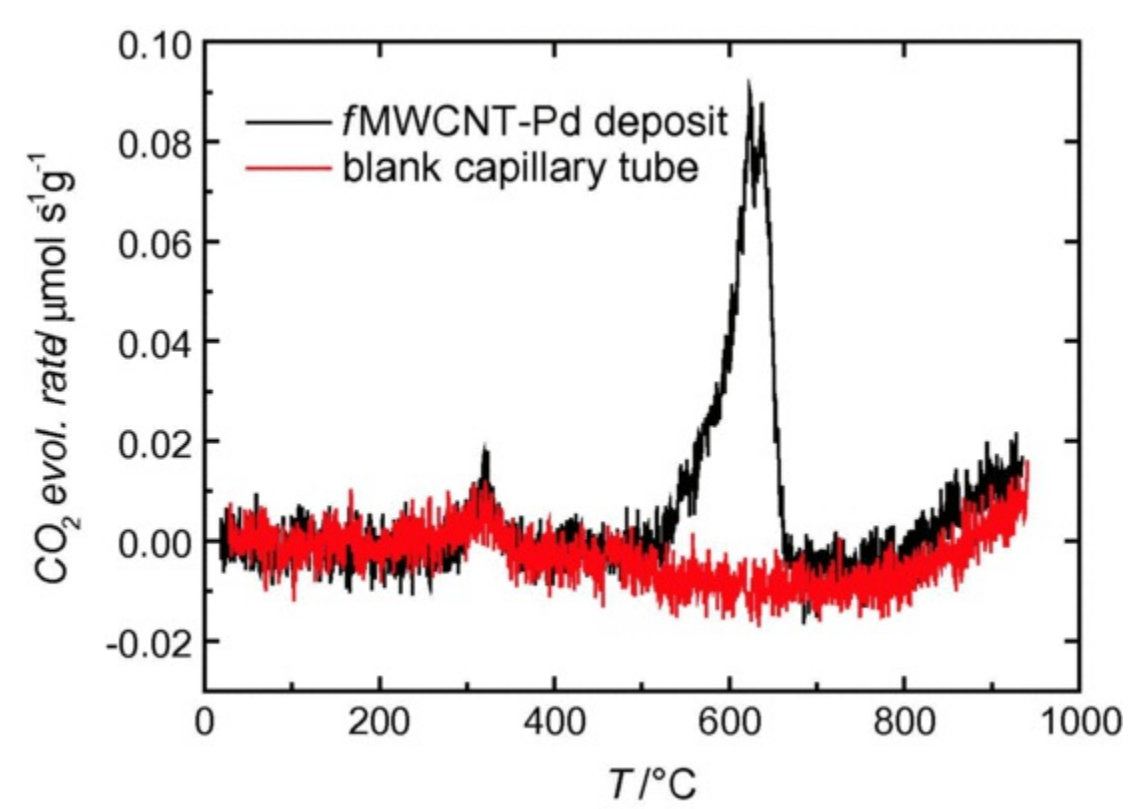

Fig. $6 \mathrm{CO}_{2}$ desorption rate profile as a function of the temperature, during the combustion of silica capillary tubes in synthetic air. (A color version of this figure can be viewed online.)

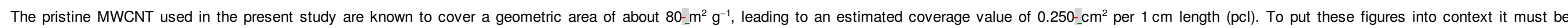

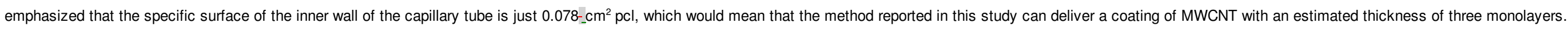

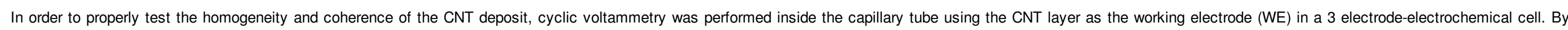

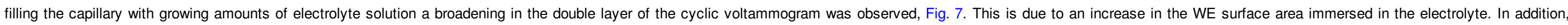

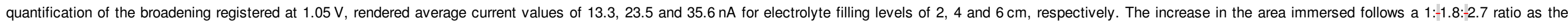

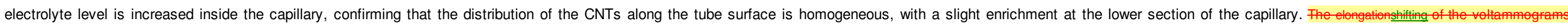

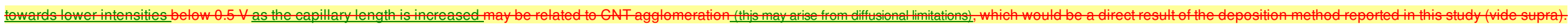




\section{ELSEVIER_CARBON_8465}

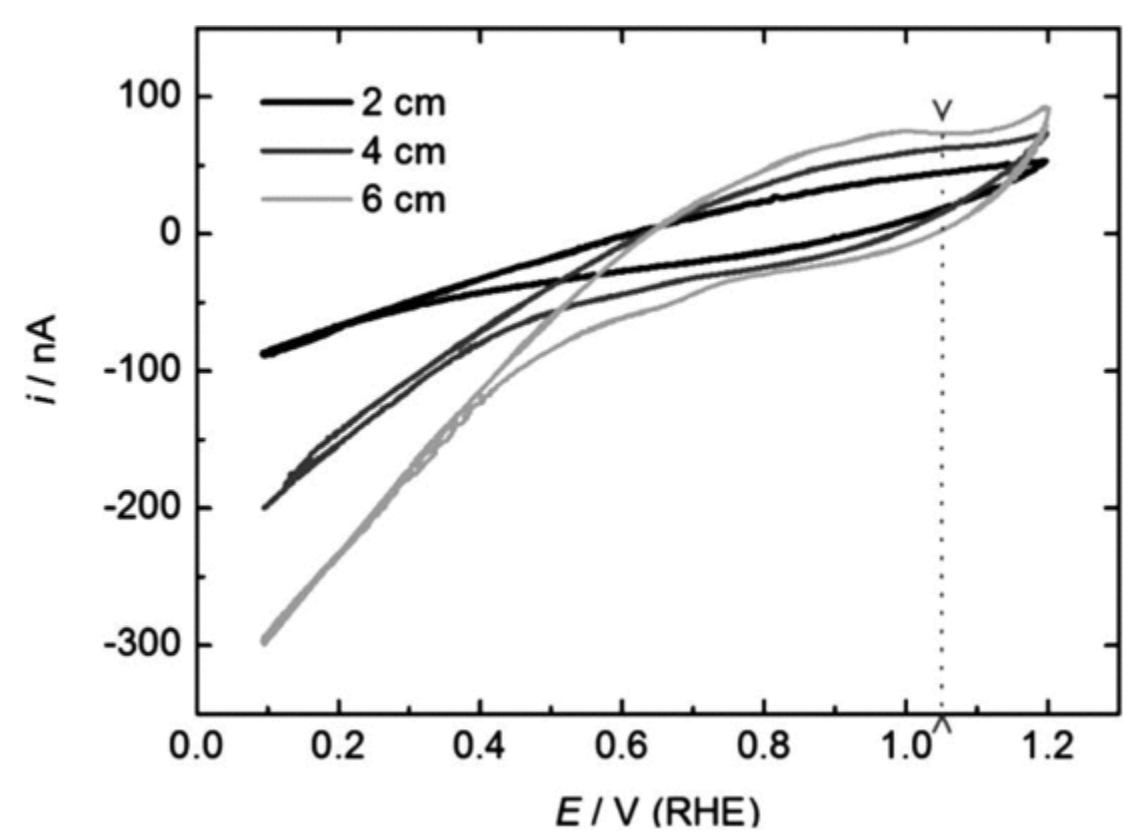

Fig. 7 Cyclic voltammograms obtained in $0.5 \mathrm{M} \mathrm{H}_{2} \mathrm{SO}_{4}$ for the capillary tube coated with $\mathrm{AMWCNT}$-Pd, for increasing levels of the electrolyte inside the tube. Scan rate of $10 \mathrm{mV} \mathrm{s}^{-1}$.

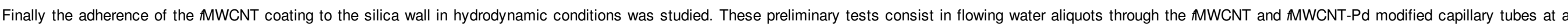

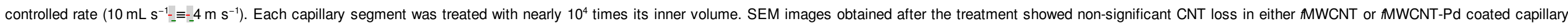

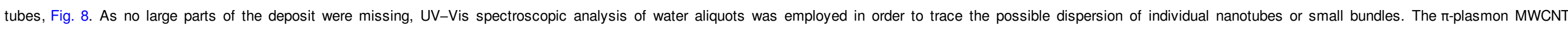

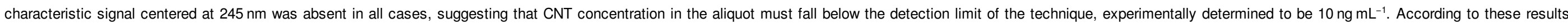

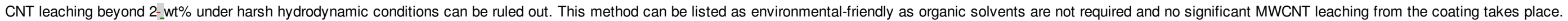




\section{ELSEVIER_CARBON_8465}
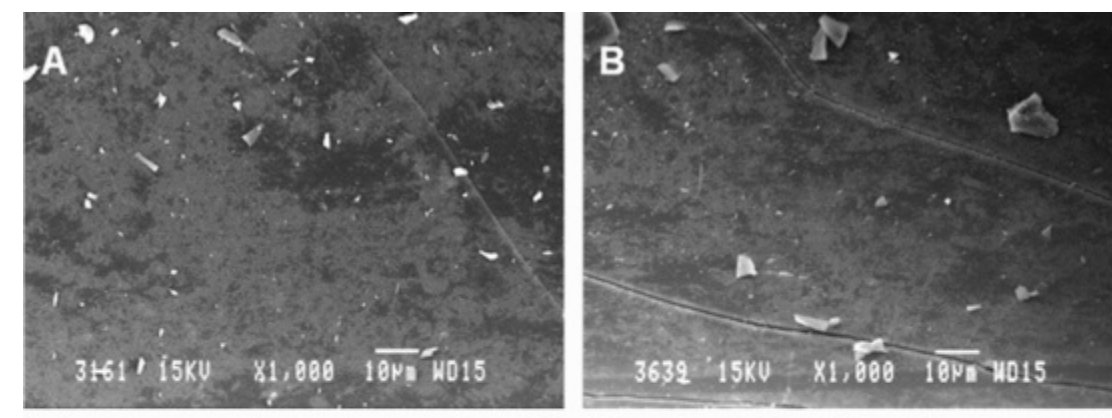

C

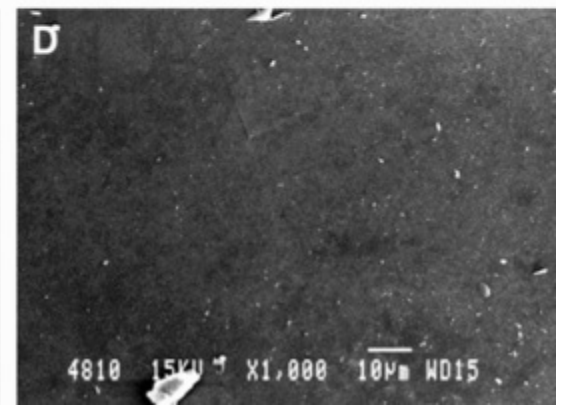

$4922 \quad 15 \mathrm{KU} \quad \mathrm{X} 1,808 \quad \overline{18 \mathrm{Na}}, \mathrm{ND} 15$

Fig. 8 SEM images corresponding to fused silica capillary tubes coated with AMWCNT before (A) and after (B) the hydrodynamic treatment, and with AMWCNT-Pd before (C) and after (D) the same treatment.

\section{Conclusion}

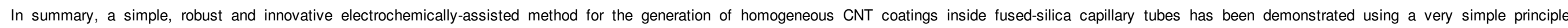

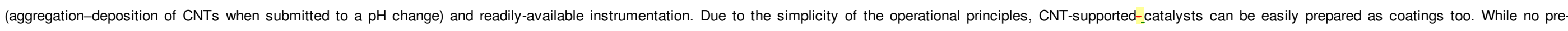

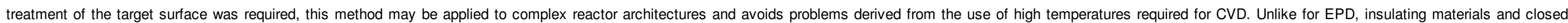

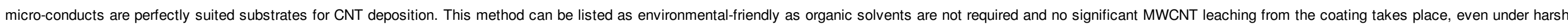

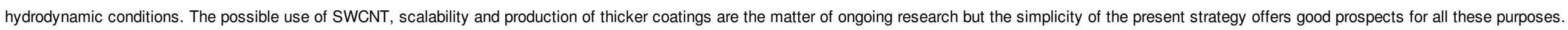

\section{Acknowledgments}

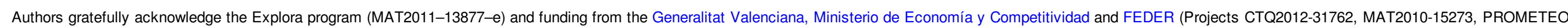
/2009/047 and RyC 2009-03913).

\section{References}

[1]

G.M. Whitesides, The origins and the future of microfluidics, Nature 442 (7101), 2006, 368-373.

[2]

A.J. deMello, Control and detection of chemical reactions in microfluidic systems, Nature 442 (7101), 2006, $394-402$.

[3]

J. Yoshida, A. Nagaki, T. Iwasaki and S. Suga, Enhancement of chemical selectivity by microreactors, Chem Eng Technol 28 (3), 2005, 259-266. 


\section{ELSEVIER_CARBON_8465}

R.L. Hartman, J.P. McMullen and K.F. Jensen, Deciding whether to go with the flow: evaluating the merits of flow reactors for synthesis, Angew Chem Int Ed $\mathbf{5 0}$ (33), 2011 , $7502-7519$.

[5]

R.L. Hartman and K.F. Jensen, Microchemical systems for continuous-flow synthesis, Lab Chip 9 (17), 2009, 2495-2507.

[6]

C. Wiles and P. Watts, Continuous flow reactors, a tool for the modern synthetic chemist, Eur J Org Chem 2008 (10), 2008, 1655-1671.

[7]

P. Watts and S.J. Haswell, The application of microreactors for small scale organic synthesis, Chem Eng Technol 28 (3), 2005, $290-301$.

[8]

E. Verpoorte, Microfluidic chips for clinical and forensic analysis, Electrophoresis 23 (5), 2002, 677-712.

[9]

S.E. McCalla and A. Tripathi, Microfluidic reactors for diagnostics applications, Annu Rev Biomed Eng 13 (1), 2011, 321-343.

[10]

A. Kundu, J.H. Jang, J.H. Gil, C.R. Jung, H.R. Lee, S.-H. Kim, et al., Micro-fuel cells-current development and applications, J Power Sources 170 (1), $2007,67-78$.

[11]

D.C. Walther and J. Ahn, Advances and challenges in the development of power-generation systems at small scales, Prog Energy Combust Sci 37 (5), $2011,583-610$.

[12]

D.S. Peterson, Solid supports for micro analytical systems, Lab Chip 5 (2), 2005, 132-139.

[13]

K.B. Mogensen and J.P. Kutter, Carbon nanotube based stationary phases for microchip chromatography, Lab Chip 12 (11), 2012, 1951-1958.

[14]

S.S. Xie, B.H. Chang, W.Z. Li, Z.W. Pan, L.F. Sun, J.M. Mao, et al., Synthesis and characterization of aligned carbon nanotube arrays, Adv Mater 11 (13), 1999 , $1135-1138$.

[15]

N.R. Franklin and H. Dai, An enhanced CVD approach to extensive nanotube networks with directionality, Adv Mater 12 (12), 2000, 890-894.

[16]

M. Kumar and Y. Ando, Chemical vapor deposition of carbon nanotubes: a review on growth mechanism and mass production, J Nanosci Nanotechnol 10 (6), $2010,3739-3758$.

[17]

B. Gao, G.Z. Yue, Q. Qiu, Y. Cheng, H. Shimoda, L. Fleming, et al., Fabrication and electron field emission properties of carbon nanotube films by electrophoretic deposition, Adv Mater 13 (23), 2001 , 1770-1773.

[18]

A.R. Boccaccini, J. Cho, J.A. Roether, B.J.C. Thomas, E. Jane Minay and M.S.P Shaffer, Electrophoretic deposition of carbon nanotubes, Carbon 44 (15), 2006, 3149-3160.

[19]

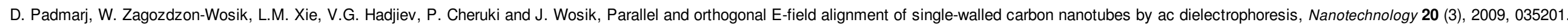




\section{ELSEVIER_CARBON_8465}

\section{[20]}

M. Karwa, Z. Iqbal and S. Mitra, Selective self-assembly of single walled carbon nanotubes in long steel tubing for chemical separations, J Mater Chem 16 (28), $2006,2890-2895$.

[21]

H. Becker and L.E. Locascio, Polymer microfluidic devices, Talanta 56 (2), 2002, 267-287.

[22]

C. André, G. Lenancker and Y.C. Guillaume, Non-covalent functionalisation of monolithic silica for the development of carbon nanotube HPLC stationary phases, Talanta 99, $2012,580-585$.

[23]

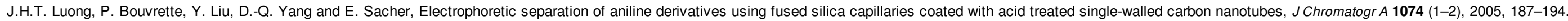

[24]

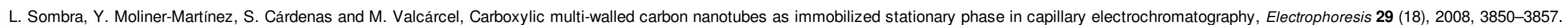

[25]

S. Peulon and D. Lincot, Mechanistic study of cathodic electrodeposition of zinc oxide and zinc hydroxychloride films from oxygenated aqueous zinc chloride solutions, $J$ Electrochem Soc 145 (3), $1998,864-874$.

[26]

L. Liu, R. Toledano, T. Danieli, J.-Q. Zhang, J.-M. Hu and D. Mandler, Electrochemically patterning sol-gel structures on conducting and insulating surfaces, Chem Commun 47, $2011,6909-6911$.

[27]

X.-L. Luo, J.-J. Xu, J.-L. Wang and H.-Y. Chen, Electrochemically deposited nanocomposite of chitosan and carbon nanotubes for biosensor application, Chem Commun 16, 2005, $2169-2171$.

[28]

V. Urbanova, M. Etienne and A. Walcarius, One step deposition of sol-gel carbon nanotubes biocomposite for reagentless electrochemical devices, Electroanalysis 25, 2013 , 85-93.

[29]

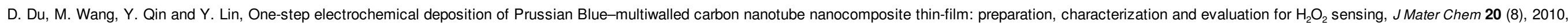
$1532-1537$.

[30]

T. Casagrande, G. Lawson, H. Li, J. Wei, A. Adronov and I. Zhitomirsky, Electrodeposition of composite materials containing functionalized carbon nanotubes, Mater Chem Phys 111 (1), 2008 , 42-49.

[31]

M.A. Aziz and H. Yang, Surfactant and polymer-free electrochemical micropatterning of carboxylated multi-walled carbon nanotubes on indium tin oxide electrodes, Chem Commun 7, 2008, 826-828.

[32]

S.W. Lee, B.-S. Kim, S. Chen, Y. Shao-Horn and P.T. Hammond, Layer-by-layer assembly of all carbon nanotube ultrathin films for electrochemical applications, J Am Chem Soc 131, $2009,671-679$.

[33]

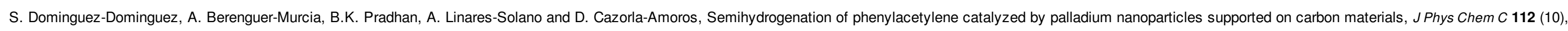
2008, 3827-3834.

[34]

I. Miguel-García, Á. Berenguer-Murcia and D. Cazorla-Amorós, Preferential oxidation of CO catalyzed by supported polymer-protected palladium-based nanoparticles, App/ Catal B 98 (3-4), 2010, 161-170. 


\section{ELSEVIER_CARBON_8465}

\section{Queries and Answers}

Query: Please confirm that given name(s) and surname(s) have been identified correctly.

Answer: All authors' names and surnames have been checked. They are all correct.

Query: Please check the edit made in the affiliation, and correct if necessary.

Answer: The edit made in the affiliation is satisfactory. No changes are needed

Query: Please note that as Refs. [3] and [8] were identical, the latter has been removed from reference list and ensuing references have been renumbered.

Answer: Please excuse this mistake. We thank the editorial staff for identifying this situation and correcting it which such efficiency. 